\title{
Immobilization of tungsten trioxide on the surface of mesoporous silica: structural investigation of the role of crystalline water on photocatalyst stability
}

\author{
Oussama Oulhakem \\ Materials Nano-Materials unit, Energy Research Centre. Faculty of Sciences, Mohammed V University in Rabat, B.P. 1014 Rabat, \\ Morocco \\ Oussama.oulhakem@um5s.net.ma
}

Tungstite $\left(\mathrm{WO}_{3} \cdot \mathrm{H}_{2} \mathrm{O}\right)$, was successfully immobilized on the surface of mesoporous Silica $\mathbf{S i O}_{2} / \mathbf{W O}_{3}$ by in-situ reaction using poly (ethylene oxide) as polymeric template and $\mathrm{Na} 2 \mathrm{WO} 4$ as precursor and immobilized tungsten trioxide $\mathbf{S i O}_{2} / \mathbf{W O}_{3}-\mathbf{C}$ was obtained by calcination of $\mathrm{SiO}_{2} / \mathbf{W O}_{3}$ at $350^{\circ} \mathrm{C}$. The as-obtained materials were characterized by $\mathrm{N}_{2}$ sorption, SEM, PXRD, FT-IR, UV-Visible and TGA.

Structural characterization of both materials indicates the succeed immobilization of tungstite and tungsten trioxide in amorphous silica. The diffraction picks in $\mathbf{S i O}_{2} / \mathbf{W O}_{3}$ are arising from two different phases corresponding to $\mathrm{WO}_{3}$ and $\mathrm{WO}_{3} \cdot \mathrm{H}_{2} \mathrm{O}$, Rietveld refinement assume the orthorhombic crystal lattice for both compounds to with parameters value $a=5.25 \AA, b=10.72 \AA, c=5.13 \AA$ for $\mathrm{WO}_{3}$ and $\mathrm{a}=5.25 \AA, \mathrm{b}=10.72 \AA, \mathrm{c}=5.13 \AA$ for $\mathrm{WO}_{3} \cdot \mathrm{H}_{2} \mathrm{O}$. phases quantification assumes the presence of tungstite $\left(\mathrm{WO}_{3} \cdot \mathrm{H}_{2} \mathrm{O}\right)$ as a majority phase by $75.3 \%$, which allow us to investigate it crystallographic structure. The crystal structure of the immobilized tungstite is generally formed by layers of distorted octahedral building blocks of $\mathrm{WO}_{6}$ in which one axial oxygen position is occupied by water molecule. After calcination at $330^{\circ} \mathrm{C}$ a phase transformation to the monoclinic structure is observed and water molecules are eliminated from the structure, lattice parameters obtained after Rietveld refinement are $\mathrm{a}=7.32 \AA, \mathrm{b}=7.54 \AA, \mathrm{c}=3.85 \AA$.

The as-prepared materials are highly efficient in the oxidative photo-degradation of sulfamethazine in water with an efficiency of $92.14 \%$ and $92.84 \%$ for $\mathbf{S i O}_{2} / \mathbf{W O}_{3}$ and $\mathbf{S i O}_{2} / \mathbf{W O}_{3}-\mathbf{C}$ respectively, with different stability aspect. Indeed, $\mathbf{S i O}_{2} / \mathbf{W O}_{3}-\mathbf{C}$ show a poor stability when it reused for 6 times due to leaching problem. In the other hand $\mathbf{S i O}_{2} / \mathbf{W O}_{3}$ could be reused with a small loss of activity after 6 cycles of photocatalysis. The stability difference is due to crystallographic structure differences that is characterized by the presence of water molecules in $\mathrm{SiO}_{2} / \mathbf{W O}_{3}$ and its absence on $\mathrm{SiO}_{2} / \mathbf{W O}_{3}-\mathbf{C}$. The good stability can be attributed to the strong van-derwalls interaction between the oxygen of silica network and the hydrogen of water molecule encapsulated in tungstite structure.
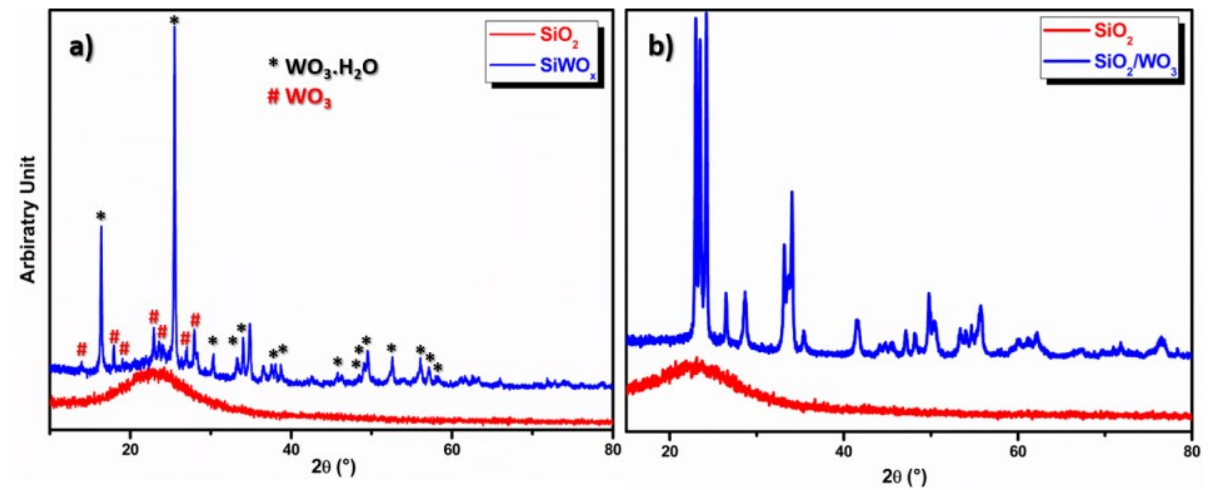

Figure 1: XRD pattern (a) $\mathrm{SiO}_{2} / \mathrm{WO}_{3}$ and (b) $\mathrm{SiO}_{2} / \mathrm{WO}_{3}$

Keywords: tungsten trioxide, tungstite, photocatalysis, sulfamethazine 